\title{
Pre-APARENCIA (VOR-SCHEIN) E ENIGMA (RATSEL) NA OBRA DE ARTE: UTOPIA E ESTÉTICA EM ERNST BLOCH E THEODOR W. ADORNO ${ }^{1}$
}

\author{
Ubiratane de Morais Rodrigues (UFMA) ${ }^{2}$ \\ ubiratanerodrigues@gmail.com
}

Resumo: Este artigo objetiva apresentar a utopia no horizonte estético de Ernst Bloch e T. W. Adorno a partir da abordagem dialética das obras $\mathrm{O}$ Principio Esperança (Das Prinzip Hoffnung) e da Teoria Estética (Ästhetische Theorie). Parte-se da origem e dos desdobramentos dos conceitos de Pré-Aparência (Vor-Schein) e Enigma (Rätsel) e suas relações com a utopia. A noção PréAparência (Vor-Schein) está intimamente ligada aos sonhos acordados que são os modeladores da arte. Como modeladores da arte, os sonhos diurnos antecipam um mundo melhor que a arte antecipa pela Pré-Aparência (Vor-Schein) do visível. Em Adorno, partimos da relação entre o conteúdo de verdade e Enigma (Rätsel) para encontrar um nexo entre esta relação e a utopia. Assim, nossa hipótese interpretativa é que no horizonte estético de Bloch e Adorno a utopia aproxima estes dois filósofos.

Palavras-chave: Estética; Enigma (Rätsel); Pré-Aparência (Vor-Schein); Utopia.

\section{INTRODUCุ̃̃O}

E onde a arte não é desperdiçada como ilusão, o belo e até o sublime transmitem uma noção da liberdade futura. Frequentemente torneada, nunca encerrada [...]. (BLOCH, 2005, p. 214).

Ernst Bloch e Theodor Adorno. A sentença pode ser dis-

\footnotetext{
${ }^{1}$ Recebido: 09-02-2016/ Aceito: 15-04-2016/ Publicado on-line: 28-08-2016.

${ }^{2}$ Ubiratane de Morais Rodrigues é Professor Assistente de Filosofia da Universidade Federal do Maranhão, Grajaú, MA, Brasil.
} 
juntiva ou conjuntiva. Para nós são as duas ao mesmo tempo. Embora os vejamos frequentemente denominados de otimista e pessimista, um filósofo da esperança e o outro da barbárie, não abordaremos a filosofia destes dois pensadores pelos discursos acadêmicos da disjunção, preconceitos políticos, nem pela confluência irrefletida de suas teses. Nossa abordagem se orienta pela interpretação dialética de suas obras, especificamente a Teoria Estética (Ästhetische Theorie) de T. W. Adorno e O Principio Esperança (Das Prinzip Hoffnung) de Ernst Bloch.

Não desconsideramos as diferenças teóricas destes dois filósofos, nem poderíamos. Mas, diante da leitura das duas obras supracitadas, chamou-nos atenção a possibilidade de aproximá-los pelo caminho da estética .

A relação entre Adorno e Bloch foi deveras complicada; de início havia uma forte amizade e cumplicidade teórica, mas com o tempo a amizade transformou-se em silêncio e mágoa. O primeiro encontro entre os dois ocorreu em novembro de 1928; depois de algum tempo de diálogos, a amizade teve rompimento nos Estados Unidos, quando os dois estavam exilados. Ambos retomaram um diálogo em público somente em 1964 por ocasião de um debate em uma rádio alemã. No Brasil, esta relação é quase desconhecida, temos muitos artigos e comentários sobre a relação de Adorno com outros contemporâneos, como por exemplo, Walter Benjamin. Assim como fez Michel Löwy, que até o momento é o único que possui um artigo apontando algumas relações entre Bloch e Adorno e que foi traduzido para o português no Brasil, nos propomos a contribuir para o conhecimento filosófico destes dois pensadores e, mais especificamente em um tema de extrema importância para os dois: a estética. Salienta-se que não se empregará uma exa- 
ustiva análise dos conceitos fundamentais dos dois filósofos, visto que o nosso objetivo é a aproximação desde a utopia e a estética, e não a validação teórica de ambos os autores. Assim, movimentar-se-ão conceitos nos limites necessários para a sustentação de nosso objetivo.

Ernst Bloch e Theodor Adorno: luzes do Romantismo, artigo de Löwy, parte das reflexões sobre Romantismo e Iluminismo, onde segundo ele, embora com abordagens distintas, existe uma dialética entre Romantismo e Iluminismo em ambos os autores, e, que a diferença profunda entre os dois é que Bloch "[...] tenta colocar a força crítica do Iluminismo a serviço da 'corrente quente' romântica, [...] enquanto Adorno [...] se propõe a empregar a força contestatória do romantismo a serviço dos objetivos do Iluminismo." (LÖWY, 2009, p. 25) .

Löwy nos lembra que Adorno escreveu dois artigos manifestando simpatia e reservas à Bloch, um ensaio em 1960 e outro em 1965. O primeiro deu-se pela ocasião da reedição do livro Vestígios (Spuren), de 1912. O segundo foi sobre o Espirito da Utopia (Geist der Utopie), de 1918. O que nos interessa no momento é apontar com Löwy que Adorno apoiava a ideia de utopia de Bloch, e que dele se nutriu. E ainda, apresentar a tensão entre negatividade e utopia, negatividade e esperança apenas como tensão, e não como pares opostos irreconciliáveis e mutuamente excludentes. A citação abaixo revela um reconhecimento de dívida, assim sobre o Espirito da Utopia, Adorno entoava: "[...] Eu me apropriei de tal forma desta base, anteriormente a qualquer conteúdo teórico, que penso jamais ter escrito nada que não se reportasse a ela, de maneira latente ou manifesta". (ADORNO apud LÖWY, 2009, p. 24).

Adorno não ficou só nos elogios, também teceu críticas 
a Bloch, porém, tais críticas não cabem aqui. Mas é fundamental apontar que, mesmo se nutrindo da ideia de utopia de Bloch, Adorno caminha pela negatividade, o que para os leitores não habituados com sua obra, gera uma oposição radical ao pensamento de Bloch. Oposição esta que é desconstruída, pelo menos em parte, pela precisa observação de Löwy e Max Blechman na introdução da Revue Europe (2008), onde os autores afirmam que: "negatividade e utopia são dialeticamente inseparáveis, não se pode verdadeiramente criticar a realidade social sem ter, implícita ou explicitamente, uma paisagem do desejo [...] E inversamente: não pode existir uma autêntica utopia sem o trabalho da negatividade [...]”. (LÖWY E BLECHMAN, 2008, p. 03. Grifo dos autores) .

Embora Löwy e Blechman tenham anotado uma reciprocidade (réciprocité) entre os dois autores, o próprio Löwy, introduzindo o livro de Arno Münster sobre Adorno, reconheceu a crítica deste autor à ideia de reciprocidade (réciprocité) entre Adorno e Bloch feita na introdução da Revue Europe, de 2008; entretanto, acrescentou em seguida: "[...] mas me parece difícil negar a presença de um momento utópico no coração da negatividade de Adorno. O ceticismo de Adorno não diz respeito tanto a utopia, como tal, mas aos movimentos práticos que tentam realizá-la." (LÖWY, 2012, p. 05).

No debate na rádio alemã, intitulado Falta alguma coi$s a^{3}$, tendo como moderador Horst Krüger, Bloch e Adorno

\footnotetext{
${ }^{3}$ Aqui utilizamos o debate entre Adorno e Bloch intitulado "Something's Missing: a Discussion between Ernst Bloch and Theodor W. Adorno on the Contradictions of Utopian Longing (1964)", traduzido do alemão por Jack Zipes and Frank Mecklenburg e publicado no livro: Bloch, Ernst. The Utopian Function of Art and Literature: Selected Essays. Studies in contemporary German social thought. Cambridge, Mass.: MIT Press, 1988.
} 
discutiram justamente sobre utopia. O diálogo segue um tom amistoso, embora em alguns momentos haja complementos de falas, onde parecem sempre acordar em pontos de vista sobre a utopia. Salientamos que, mesmo em um debate amistoso, onde nem todas as categorias dos autores são postas em questão, é possível entrever a utopia no pensamento dos dois filósofos, pois, mesmo que por caminhos distintos, há uma preocupação latente de ambos em proteger a utopia de sua banalização. Quanto à negatividade no pensamento de Bloch, e isto é interessante para nós, uma vez que possibilita ainda mais um diálogo entre Bloch e Adorno desde as categorias adornianas, Löwy acrescenta que o complemento

[...] necessário do pensamento antecipatório voltado para o mundo futuro é o olhar crítico sobre este mundo: a vigorosa acusação da civilização industrial/ capitalista e de suas injustiças é um dos temas principais (frequentemente desconhecido) do Princípio Esperança. (LÖWY, 2009, p. 17. Grifo do autor).

Não temos dúvidas da possibilidade de um diálogo entre Adorno e Bloch sobre a utopia. Entretanto, cumpre-nos investigar se, no âmbito da estética, os conceitos Enigma (Rätsel) e Pré-Aparência (Vor-Schein) para além de suas dialéticas com a verdade apontam vestígios utópicos na obra de arte, e como eles aproximam e distanciam nossos dois filósofos. Nesse sentido, dividiremos esta exposição em três partes: na primeira parte apresentaremos o conceito de PréAparência (Vor-Schein) em Ernst Bloch e como este conceito se liga à utopia. No segundo momento, apresentaremos o conceito de Enigma (Rätsel) em Adorno e como este estabelece sua relação com a utopia. No terceiro e último momento, apresentaremos algumas considerações apontando a aproximação e distanciamento em Bloch e Adorno com re- 
lação à utopia, e o tratamento desta com os conceitos em questão no campo da estética.

\section{PRÉ-APARÊNCIA (VOR-SCHEIN) NA OBRA DE ARTE}

A noção de Pré-Aparência (Vor-Schein) que, para nós, marca esta relação - arte e utopia - está intimamente ligada aos sonhos acordados que, diferente dos sonhos diurnos, são os modeladores da arte. Eles são prenhes de conteúdo artístico, uma vez que, "[...] abrange desde o sonho desperto do tipo cômodo, trivial, rude, fugaz, despropositado e paralisante, até o tipo responsável, engajado na causa com ações precisas e o tipo modelador da arte." (BLOCH, 2005, p. 89). Como modeladores da arte, os sonhos diurnos cumprem a função de apresentar antecipadamente um mundo melhor, que a arte anteciparia pela Pré-Aparência (Vor-Schein) do visível, pois nela seriam comunicados os interesses utópicos de uma vida melhor. Ora, "essa pré-aparência é possível justamente porque a arte leva os seus temas até o fim, em figuras, situações, atos, paisagens, fazendo com que se efetivem no sofrimento, na felicidade e também por sua relevância." (BLOCH, 2005, p. 212).

Salienta-se que, levar até o fim na obra de arte, não significa um acabamento formal da obra, mas uma concretização possível de abertura para o futuro, ou seja, "[...] toda grande obra de arte, para além da sua essência manifesta, ainda foi concebida sobre uma latência do aspecto vindouro vale dizer: sobre os conteúdos de um futuro que no seu tempo ainda não haviam surgido." (BLOCH, 2005, p. 100. Grifo do autor). E, nesse sentido, Bloch é categórico na re- 
lação entre os sonhos diurnos e a arte: o sonho diurno como prelúdio da arte visa assim, "[...] à melhoria do mundo; [...] em toda parte o sonho desperto e a expansão do mundo são pressupostos da obra de artre executada como experimento imaginário o mais próximo possivel da perfeição [...]." (BLOCH, 2005, p. 96. Grifos do autor).

A partir dessa possibilidade aberta, a arte ganha contornos utópicos, pois sua iluminação permanece mesmo depois de exposta; ela aponta para o ainda-não. $\mathrm{O}$ aberto para o ainda-não só é possível numa consciência ciente da falta e das possibilidades concretas da libertação da carência; esta consciência, Bloch caracteriza de ainda-nãoconsciente (Noch-Nicht-Bewußten) que, ao contrário do nãomais-consciente (Nicht-Mehr-Bewußten) é “[...] o préconsciente do vindouro, o lugar psíquico de nascimento do novo." (BLOCH, 2005, p. 117). É a partir desta concepção que a função utópica da arte ganhará dignidade. Sendo assim, podemos questionar: como a arte se encaixa em nossa atualização do ainda-não-consciente (Noch-Nicht-Bewußten)?

Aqui, é preciso deixar claro que, para Bloch, nem toda obra de arte carrega um resíduo de utopia concreta, nem é fruto de uma produtividade plena do ainda-não-consciente (Noch-Nicht-Bewußten), produtividade que é inspiração do futuro. Aqui adiantamos que Bloch propõe uma estética coerente com suas aspirações marxistas, uma estética onde a força criadora esteja prenhe de utopia concreta para transformação do mundo. Nesse sentido, a obra de arte não tem como referência somente o passado, mas o futuro, aquilo "que-ainda-não-veio-a-ser". É justamente a partir do marxismo que Bloch pode passar da consciência antecipadora (das Antizipierende Bewusstsein) à transformação do mundo.

A obra de arte cumprirá sua função utópica através da 
Pré-aparência (Vor-Schein) nela imanente. Posto que, "sem a função utópica, não se pode explicar nenhum excedente intelectual que pese sobre o que foi alcançado ou sobre o que é existente, por mais que esse excedente esteja cheio de aparência em vez de pré-aparência." (BLOCH, 2005, p. 149).

A arte, por levar suas imagens até o fim, ilumina o possível real, que "[...] é processo e processo é a mediação vastamente ramificada entre o presente, o passado pendente e sobretudo o futuro possível. No seu front processual, todo real passa a ser o possível [...]." (BLOCH, 2005, p. 194). Isso permite que a arte tenha seu correlato no mundo material e possível de ser concretizado. Para melhor compreensão dessa assertiva, Bloch diferencia o objetivamente possível e o possível real, onde o primeiro é "[...] tudo aquilo cuja coerência pode ser cientificamente esperada [...]" e o segundo "[...] é tudo aquilo cujas condições ainda não estão integralmente reunidas na esfera do próprio objeto [...]." (BLOCH, 2005, p. 195. Grifo do autor).

A partir desta diferenciação, nosso autor pode fundamentar suas teses sobre a questão da verdade na/da obra de arte e sua relação com a utopia. Esta não se encontra na esfera do abstracionismo, mas no possível real do mundo, pois, "[...] no fenômeno chamativo da arte, a utopia como determinação do objeto, [...] defronta-se com um problema de comprovação especialmente fecundo." (BLOCH, 2005, p. 212). E assim, "[...] a resposta à pergunta estética pela verdade tem o seguinte teor: em toda parte, a aparência artística não é mera aparência, mas uma significação envolta em imagens, designável somente mediante imagens, do que foi impulsionado para a frente [...]." (BLOCH, 2005, p. 212).

A Pré-Aparência (Vor-Schein) é um recurso filosófico con- 
tra o pessimismo e a degradação da arte, ela nasce no seio da discussão e diferenciação fundamental entre ilusão e aparência. $\mathrm{O}$ que faz com que, mesmo que a obra seja aparência, não continue ilusão, como afirma nosso autor. Ou seja, pela fundamentação utópica, a arte continua aparência, mas introduz no mundo uma iluminação cujo correlato é o possível real, por isso a arte para Bloch é "não-ilusão" .

Bloch coloca a arte para além do imediatismo de sua criação e apreciação, "[...] pois permanece mesmo após ser desfrutada. Mesmo nos casos mais aprazíveis, ela ainda se estende para uma terra "pintada diante dos olhos." (BLOCH, 2005, p. 208). Essa concepção é concretizada com a entrada dos sonhos diurnos, sonhos desejantes que ao contrário dos políticos "[...] já assumiu caráter de obra, já se tornou um belo que ganhou forma." (BLOCH, 2005, p. 208. Grifo do autor). Ele nos chama atenção para o caráter dessa obra, questionando-nos se ela poderia ser mais um jogo de aparência, colocando-nos no cerne do problema ontológico da obra de arte. Isso é possível, porque ele já apontou para a continuidade da obra de arte após sua consumição. A questão da verdade da/na obra de arte entra em cena, e o problema estético arte/realidade surge com uma necessidade de resposta ugente ao projeto utópico concreto de Bloch. A partir do questionamnto sobre o belo acabamento na obra de arte e do ilusório nela contido, ele apropriandose da tradição filosófica estética, asserta que "[...] os artistas estão conjurados com a aparência do começo ao fim: eles não têm nenhuma propensão para a verdade, mas a propensão contrária." (BLOCH, 2005, p. 209) .

Nosso autor encontrará no Iluminismo, material para estabelecer um diálogo profundo relativo à relação arteverdade. Ele percebeu que, neste, havia muitas objeções 
empíricas e racionais contra a arte. $\mathrm{O}$ centro desta hostilidade à arte é exemplificado na pergunta matemáticoracional "Qu'est-ce que cela prouve?". Pergunta pertencente à escola racionalista moderna omissora da estética e sintoma de estranhamento à arte. Ele não esquece a linha racionalista da estética como disciplina filosófica inaugurada por Baumgarten, que segue os mesmos passos de desqualificação racional da arte. Assim, tanto racionalistas quanto empiristas, produziram ambientes para a redução da arte ao mundo do meramente ilusório e sem estatuto de verdade. Entretanto, não só no âmbito da razão a arte foi desqualificada; para Bloch, a fé também contribuiu nessa desqualificação. Sua conclusão não poderia ser outra: "portanto, em formas tão diversificadas [...] manifestam-se as reclamações da verdade contra o belo. E, por serem reclamações da verdade [...] ainda assim elas estão unidas na vontade imbuída de seriedade contra a aparência." (BLOCH, 2005, p. 210).

Segundo Bloch, os artistas também não haviam resolvido a questão estética da verdade. Para ensaiar uma resposta a essa questão, ele cita três obras (A Ressureição de Lázaro de Giotto, o Paraíso de Dante e o céu na parte final do Fausto) questionando a relação destas com a pergunta filosófica pela verdade, aqui ele recupera a pergunta matemáticoracionalista "Qu'est-ce que cela prouve?", e reelabora o problema arte/verdade. Assim, "a pergunta pela verdade da arte se transforma, no nível filosófico, [...] na pergunta pelo seu grau de realidade em meio à realidade de modo algum unidimensional do mundo, na pergunta pelo lugar do seu correlato como objeto." (BLOCH, 2005, p. 212) .

O conceito Pré-Aparência (Vor-Schein) liga a arte ao seu correlato no mundo concreto, sendo que a obra de arte como fruto de uma práxis humana, antecipa utopicamente 
o que ainda-não-é, mas que pela fundamentação no possível real ainda não é no presente, mas, segundo a tendência e latência pode se concretizar no futuro. A arte, dessa forma, carrega a esperança e ilumina o mundo antecipando fragmentos do real ainda não existente. É forçoso salientar que a Pré-Aparência (Vor-Schein) não está necessariamente na totalidade da obra e que mesmo no fragmento da obra, há o utópico .

A Pré-Aparência (Vor-Schein) faz da obra de arte um fragmento do possível real, uma passagem da obra para o mundo, liga o fragmento ao seu correlato no mundo do qual ele faz parte, posto que "a utopia concreta como determinação do objeto pressupõe o fragmento concreto como determinação do objeto e o envolve, ainda que certamente como um fragmento no final das contas passível de anulação." (BLOCH, 2005, p. 212). Ora, "o elemento ilusório das obras de arte concentrou-se na pretensão a serem um todo" (ADORNO, 2008, p. 159). Não seria o fragmento a melhor maneira de se escapar à tentativa de totalização da obra de arte? Uma maneira de sustentar a arte como aparência sem cair no meramente ilusório?

Cumpre-nos agora examinar o conceito de Enigma (Rätsel) em Adorno, que diferentemente de Bloch, não é tão explícito nessa relação entre arte e utopia, instigando-nos mais ainda a percorrermos a obra deste filósofo. Nosso objetivo aqui é apenas apresentar alguns elementos que apontem a utopia na estética de Adorno, já que os desdobramentos desses apontamentos não podem ser feitos em um curto espaço como este; contudo, nos serve como elementos para o objetivo central do presente artigo. 


\section{ENIGMA (RÄTSEL) NA OBRA DE ARTE}

Ao passar ao tratamento do conceito de Enigma (Rätsel), que aparece mais sistematizado e desenvolvido a partir da seção "Caráter enigmático, conteúdo de verdade; metafísica" de sua obra póstuma Teoria Estética (ADORNO, 2008, p. 183. 209), é importante notar que, logo no início da obra, Adorno afirma que: "a definição do que é arte é sempre dada previamente pelo que foi outrora, mas apenas é legitimada por aquilo em que se tornou, aberta ao que pretende ser e àquilo em que poderá talvez tornar-se." (ADORNO, 2008, p. 14) .

Há um esforço tanto em Adorno como em Bloch de resgatar a aparência da obra de arte. Este resgate só poderia ser feito se houvesse para além desta, algo de que só se pudesse ter acesso através da aparência. Note-se que, embora Bloch fale da utopia e da obra de arte como fragmento utópico, não afirma nenhum acabamento utópico, ou melhor, não aponta nenhum lugar pronto para habitação e realização plena da obra de arte. Pois esta não é acabada, porque, como nos lembra Adorno, "[...] a arte só é interpretada pela lei do movimento, não por invariantes. Determina-se na relação com o que ela não é." (ADORNO, 2008, p. 14).

Sabemos que ambos, Adorno e Bloch, utilizam-se do discurso e categorias da Filosofia para resgatar a aparência da obra de arte. Pois, suas estéticas embora não sejam as últimas determinações do otimismo, da felicidade, da reconciliação sujeito-objeto, também não brincam com orações fúnebres, e nem corroboram para o declínio do conteúdo da arte. $\mathrm{O}$ século XX acirrou a discussão sobre a verdade da obra de arte, e mais ainda sobre a própria estrutura e validade da 
arte. Não só artistas, mas também filósofos debateram muito sobre a arte no século passado; a explosão das Vanguardas Históricas é a prova testemunhal desse embate. Assim, não menos sem importância, é a categoria da aparência neste debate.

Tanto Bloch quanto Adorno sabem que a aparência não é suficiente para apresentar um conteúdo de verdade ou um fragmento de utopia, mas é na/e pela aparência da obra que adentramos na verdade da obra de arte, seja esta manifesta de forma enigmática ou na forma de Pré-Aparência (Vor-Schein). É Adorno o autor que melhor expõe a crise da aparência e, a partir desta, ele chega à exposição do caráter enigmático da obra de arte. Aqui, ao contrário de Bloch, não há antecipadamente uma função utópica na arte, mesmo sabendo que "em toda obra de arte genuína, aparece algo que não existe.” (ADORNO, 2008, p. 131) .

Adorno chama atenção para o fato de que a legitimidade "[...] da rebelião contra a aparência enquanto ilusão e o elemento ilusório desta rebelião, isto é, a esperança de que a aparência estética consiga por sua própria cabeça sair do lodaçal, confundem-se entre si." (ADORNO, 2008, p. 161162). Essa é uma discussão que não se resolverá por fáceis caminhos, pois "[...] nenhuma obra de arte possui conteúdo a não ser mediante a aparência, na própria estrutura desta." (ADORNO, 2008, p. 167). Essa asserção leva Adorno a afirmar que "[...] o centro da estética seria a salvação da aparência e o direito enfático da arte, legitimação da sua verdade, depende dessa salvação." (ADORNO, 2008, p. 167).

Esta salvação para Adorno é complexa e problemática e "só com a condição de que o seu conteúdo seja verdadeiro não metaforicamente é que a arte expulsa o fabricado, a aparência produzida pelo seu ser-feito.” (ADORNO, 2008, 
p. 167). Apresenta-se assim, a incontornável necessidade de buscar o caráter legitimador da obra de arte enquanto aparência, uma vez que "as obras de arte são aparência" (ADORNO, 2008, p. 170). Será o caráter enigmático da obra, ou melhor, o conteúdo de verdade atravessado pelo enigmático da obra que sustentará a aparência, ou ainda, a interpretação filosófica da categoria Enigma (Rätsel) na obra de arte é que, para nós, garantirá um estatuto ontológico à obra de arte. E por fim, poderá sustentar no horizonte estético adorniano a utopia.

Assim, quanto às origens desse caráter enigmático das obras de arte, Adorno não o separa da história. Para ele, "todas as obras de arte, e a arte em geral, são enigmas." (ADORNO, 2008, p. 186). Isso não significa que elas são criadas com tal intenção, nem que não são acessíveis ao público menos especialista ou totalmente leigo. Pois, "o caráter enigmático da arte não é a mesma coisa que compreender as suas obras, isto é, objetivamente, produzilas, [...] a partir da sua experiência interna [...]." (ADORNO, 2008, p. 188).

Para Adorno a relação entre o caráter enigmático e a compreensão é problemática, visto que, "quanto melhor se compreende uma obra de arte, tanto mais ela se revela segundo uma dimensão, tanto menos, porém, ela elucida o seu elemento enigmático constitutivo." (ADORNO, 2008, p. 188). Assim, ele asserta que: "[...] as obras de arte que se apresentam sem resíduo à reflexão e ao pensamento não são obras de arte. $\mathrm{O}$ enigma não é, pois, uma palavra-mestra como, na maior parte dos casos, a palavra 'problema' [...]." (ADORNO, 2008, p. 188).

O Enigma (Rätsel) leva-nos à reflexão, à inquietude interna, ao desejo da interpretação. Daí o caráter enigmático 
da obra de arte aparecer sob o "aspecto da linguagem." (ADORNO, 2008, p. 186). E como esta não se encontra exposta na obra, faz com que o conhecimento especializado seja "[...] ao mesmo tempo compreensão adequada da arte e incompreensão obtusa do enigma, neutra em relação ao que está oculto. Quem se contenta com compreender algo na arte transforma-se em evidência, o que ela de modo algum é." (ADORNO, 2008, p. 189). Assim, a busca pela decifração, ou resolução do Enigma (Rätsel) é a busca pelo incomensurável na obra, algo inalcançável, pois, “[...] Não há enigma a resolver, trata-se apenas de decifrar a sua estrutura, e tal é a tarefa da filosofia da arte." (ADORNO, 2008, p. 189).

Adorno não abre mão da intrínseca relação entre arte e Filosofia. Mas nos aponta uma chave para o entendimento do sentido do Enigma (Rätsel): a imaginação. Ora, não é essa uma categoria fundamental na constituição da utopia concreta de Bloch? Não são nos sonhos acordados, onde podemos imaginar um mundo melhor, um ainda não existente? Não que a imaginação desvende o Enigma (Rätsel), este não cabe na interpretação mas, "[...] a compreensão no sentido mais elevado, a resolução do caráter enigmático que ao mesmo tempo o mantém, está ligada à espiritualização da arte e da experiência estética, cujo médium primordial é a imaginação." (ADORNO, 2008, p. 189. Grifo do autor).

Mesmo tendo a imaginação um papel central na compreensão do sentido mais elevado do Enigma (Rätsel), o que está em jogo é o conteúdo de verdade da obra de arte. E neste ponto, Adorno eleva o Enigma (Rätsel) para além de sua composição. Para ele "na instância suprema, as obras de arte são enigmáticas, não segundo a sua composição, mas segundo o respectivo conteúdo de verdade." (ADORNO, 
2008, p. 197). Assim, para Adorno, "a questão 'para que serve tudo isso?' - transforma-se nesta - 'É, pois verdadeiro?' - questão do Absoluto, à qual toda a obra de arte reage ao desembaraçar-se da forma da resposta discursiva." (ADORNO, 2008, p. 197) .

Foi a pergunta "Qu'est-ce que cela prouve?" outrora em Bloch, que mudou a perspectiva do conteúdo de verdade na obra de arte para este pensador, parece-nos necessário que tanto esta pergunta quanto "É, pois verdadeiro?" sejam para além da racionalidade empírica, interrogações que as próprias obras colocam a si mesmas, e na espera da resposta, ou da prova, apareçam como brilho (Schein) ou Enigma (Rätsel) do ainda-não. A solução do Enigma (Rätsel), para além da organização gramatical da resposta, torna-se em Adorno, tarefa da reflexão filosófica. Em Bloch, também não foi diferente. Adorno é ainda mais incisivo: "a filosofia e a arte convergem no seu conteúdo de verdade: a verdade da obra de arte que se desdobra progressivamente é apenas a do conceito filosófico." (ADORNO, 2008, p. 201).

Partindo deste desdobramento entre o conteúdo de verdade e Enigma (Rätsel), buscamos encontrar um nexo entre este desdobramento e a utopia em Adorno. Não fugindo de seus princípios, a utopia aparece no horizonte estético de Adorno negativamente. Mas, não de todo explicitamente abandonada, visto que, ao mesmo tempo em que Adorno diz que "a arte, tal como a teoria, não está em condições de realizar a utopia; nem sequer negativamente. [...]" ele afirma: "o Novo enquanto criptograma é a imagem da decadência; só através da sua negatividade absoluta é que a arte exprime o inexprimível, a utopia." (ADORNO, 2008, p. 58). 


\section{CONSIDERAÇÕES FINAIS}

A aproximação entre Adorno e Bloch no que diz respeito à utopia pelo caminho da estética não é a única possibilidade, mas é a que para nós melhor demonstra o esforço teórico dos dois filósofos para salvaguardar a dignidade da utopia; Principalmente pelo fato da obra de arte guardar uma dialética entre a Pré-Aparência (Vor-Schein) e utopia em Bloch, e, Enigma (Rätsel) e utopia em Adorno. Optamos por apresentar essa aproximação e distanciamento pelo viés da estética por não ser explícito em estudos de nosso conhecimento e por não ter sido exposta pelos dois no diálogo na entrevista supracitada. Nesta entrevista, podemos demarcar outras duas aproximações entre Bloch e Adorno em relação à utopia, além de apontar um ponto de discordância sobre o tema.

Os dois pontos de aproximação entre Adorno e Bloch são: em relação ao conteúdo da utopia e a relação entre a morte e a utopia. O que os afasta é a relação entre técnica e utopia. Contudo, todos os três pontos são ligados por um resgate da utopia, ou seja, uma tentativa de salvar a mesma de sua depreciação atual .

Quando questionados na entrevista por Horst Krüger sobre o conteúdo da utopia, Bloch lembra de algumas de suas ideias postas na quarta parte do Princípio Esperança, intitulada Esboços de um mundo melhor, como as utopias sociais e as utopias tecnológicas, resgatando Thomas Morus e Francis Bacon (BLOCH, 2006). Mas, assim como Adorno, concorda que não há uma categoria ou conteúdo específicos como determinação última da utopia. Neste ponto, os dois filósofos concordam e se aproximam. (BLOCH, 1988, p. 7). 
O tema mais polêmico, e ao mesmo tempo o mais difícil de ser tratado para os pensadores, é a relação da utopia com a morte. Bloch é categórico quando coloca a morte no cerne de seu pensamento utópico, pois, para ele "[...] a morte representa a mais dura contra-utopia." (BLOCH, 1988, p. 9). E seguindo Bloch, Adorno acrescenta, "[...] eu acredito que sem a noção de uma vida sem restrições, livre da morte, a ideia de utopia, não pode sequer ser pensada”. (BLOCH, 1988, p. 10. Grifos do autor). Mesmo que a relação entre a utopia e a morte aproximem os dois pensadores, é preciso ressaltar que ambos desenvolvem seus pontos de vista por caminhos distintos e não os desenvolvem em sua totalidade na entrevista. O que salientamos aqui é uma aproximação inequívoca entre Adorno e Bloch neste ponto

A relação entre técnica e utopia é, na entrevista, o ponto de maior divergência entre os dois filósofos. Para Adorno, mesmo tendo se cumprido alguns sonhos acordados, o homem não se vê feliz com os mesmos. Os sonhos que a técnica conseguiu concretizar se transformaram em tédio, como por exemplo, ele cita a televisão. Bloch, ao contrário, não desconsidera a associação entre o desenvolvimento da técnica e a realização da utopia, mas deixa claro que a técnica é limitada quanto à realização dos sonhos acordados, pois ela os realizou muito parcialmente. Há ainda resíduos para serem realizados. Para nós, a divergência neste ponto pode ser uma questão de fundamento da noção de utopia, uma vez que a utopia em Bloch e Adorno tem origens distintas; o primeiro a fundamenta na ontologia do ainda-não, enquanto o segundo busca, nos rastros da história, fundamentar a sua concepção de utopia .

Embora as diferenças e discordâncias tenham aparecido 
nessa entrevista de maneira superficial, podemos notar que a preocupação central dos dois filósofos não era atacar e refutar a ideia de utopia do outro, mas salvá-la da depreciação atual em que a palavra e a ideia de utopia se encontram (BLOCH, 1988, p. 11). O que nos interessa aqui é perceber que há, entre os dois filósofos, um diálogo sobre a utopia, e que pode ser melhor explorado no horizonte estético das filosofias dos mesmos.

Assim, reforçado que a aproximação e distanciamento entre Adorno e Bloch no que se refere à questão da utopia não reverbera em equívoco teórico, retomamos o cerne de nosso problema para concluir parcialmente a questão no que diz respeito à estética. Pois, para nós, parece ser, sem dúvida, a utopia ainda algo necessário e problemático nas obras de arte, visto que para Adorno,

O que se experimenta como utopia permanece algo de negativo contra o que existe, embora lhe continue, a pertencer. Central nas antinomias atuais é o fato de que a arte deve e pretende ser utopia, e tanto mais decididamente quanto a relação real das funções impede a utopia; e que ela, porém, para não trair a utopia pela aparência e pela consolação, não tem o direito de ser utopia. Se a utopia da arte se realizasse, seria o seu fim temporal. (ADORNO, 2008, p. 58).

Em Bloch, também não há a realização da utopia através da arte, esta apenas antecipa pela Pré-Aparência (VorSchein) o ainda-não. Bloch não apresenta como deve ser a reconciliação sujeito-objeto, não transcreve um lugar pronto e acabado, não determina o indeterminável, mas aponta um horizonte de possibilidade, um possível-real. Adorno, não é tão otimista e enfático como Bloch, mas sabe que pelo "[...] fato de as obras de arte existirem mostra que o nãoente poderia existir. A realidade (Wirklichkeit) das obras de arte dá testemunho da possibilidade do possível." 
(ADORNO, 2008, p. 204). E mantendo a posição de que a utopia não pode ser representada por um conteúdo último capaz de realização, ambos se aproximam quando apresentam a dialética entre arte e utopia como passagem para a crítica social e a impossibilidade de realização da utopia no presente.

A realização do possível está separada da obra de arte, pois se ela o realizasse seria seu fim, e pela separação é que podemos adentrar no enigmático da obra de arte, pois, "o enigmático das obras de arte é o seu estar-separado. Se a transcendência nelas estivesse presente, seriam mistérios, não enigmas [...]." (ADORNO, 2008, p. 196). Assim, enigmáticas ou utópicas, as "[...] grandes obras de arte não podem mentir. Mesmo quando o seu conteúdo é aparência, possui necessariamente uma verdade de que dão testemunho as obras de arte [...]." (ADORNO, 2008, p. 200).

Tanto Adorno quanto Bloch estão envolvidos com a questão da utopia na obra de arte. Se no primeiro a utopia aparece de forma negativa apontando diretamente para uma crítica ao real, no segundo a utopia concreta é explicitamente possibilidade de superação do real com elementos materiais presentes no próprio real. Os projetos estéticos de ambos apresentam um problema central na interpretação do conteúdo utópico da obra de arte, a saber: em Adorno, o Enigma (Rätsel), e em Bloch, a Pré-Aparência (Vor-Schein).

É preciso lembrar a irredutibilidade de uma categoria à outra, embora para o autor deste artigo, ambas apareçam como mediadoras entre a obra de arte de fato e o que cada um extrai dela enquanto potencial utópico, seja na forma de negatividade, seja de forma otimista .

Bloch e Adorno, mesmo com diferenças em suas formas de abordar a relação entre arte e utopia, para nós, apa- 
recem como fundamentais e complementares para a compreensão da relação entre arte e sociedade. Pois, complementares na diferença, ajudam-nos a compreender dois movimentos fundamentais da estética marxista; de um lado a crítica ao que está posto como dado e encerrado, e de outro a abertura para a transformação do mundo. A arte cumpre sua função utópica na medida em que é capaz de fazer esse movimento imanente, cuja interpretação aponta possibilidades concretas. Seja na negação crítica do presente, seja na construção de um mundo melhor.

Essa complementaridade pode ainda ser apresentada por outra diferença expositiva destas duas perspectivas estéticas ora em análise, a saber: a matéria e a história. As duas não estão dissociadas na estética marxista, mas na exposição do problema, uma aparece como destaque em relação à outra; isso se deve à hermenêutica interna da filosofia de cada pensador. Em Adorno, o Enigma (Rätsel) está diretamente ligado à história, já que o momento histórico da produção da obra determina a complexidade do Enigma (Rätsel). Em Bloch, a Pré-Aparência (Vor-Schein) está ligada diretamente à obra de arte como fragmento do real. Isso não implica em hipótese alguma que ambos desconsiderem matéria ou história, seria absurda tal interpretação. $O$ que colocamos é a prioridade na exposição de suas concepções estéticas por uma e outra categoria. Na exposição da relação arte e utopia eles se distanciam.

Para nós, não há dúvidas da aproximação e do distanciamento entre Adorno e Bloch na relação entre arte e utopia. A entrevista de 1964 já demonstra, mesmo que parcialmente, a possibilidade de aproximação entre os dois no que diz respeito ao conteúdo da utopia e da relação entre a morte e a utopia. E que também é possível distanciá-lo 
quando a relação é entre técnica e utopia. Mas o campo da estética ainda se encontra aberto para explorarmos e aprofundarmos essa aproximação e distanciamento. Os dois pensadores, em análise, nos ajudam a compreender o movimento entre arte e utopia, e nos fornecem elementos para compreendermos nossas obras que, por várias vezes, foram interpretadas, mas, que ainda guardam a interpretação de seu caráter enigmático. Poderíamos, com risco de errar, levantar a hipótese de que o Enigma (Rätsel) da obra de arte é a utopia não decifrada, ainda não alcançada, irrealizável no mundo administrado, mas à espera, no horizonte da possibilidade. E por fim, sustentar que, no horizonte estético de Bloch e Adorno, a tensão entre negatividade e utopia aproxima e distancia estes dois filósofos, sempre torneados pela crítica e pela interpretação, mas nunca encerrados.

Abstract: This article aims to present the utopia in the aesthetic horizon of Ernst Bloch and T. W Adorno, from the dialectical approach of Principle Hope (Das Prinzip Hoffnung) and Aesthetic Theory (Ästhetische Theorie). We started from the origin and deployments of the concepts of Pre-appearance (Vor-Schein) and Enigma (Rätsel) and their connections to utopia. The preappearance (Vor-Schein) notion is closely linked to daydreams which are art modelers. As art modelers, daydreams anticipate a better world which art anticipates by the Pre-appearance (Vor-Schein) of the visible. In Adorno, we start from the relationship between the content of truth and Enigma (Rätsel) to find a link between that relationship and the utopia. So, our interpretative hypothesis is that in the aesthetic horizon Bloch and Adorno utopia approaches these two philosophers.

Keywords: Aesthetic; Enigma (Rätsel); Pre-appearance (Vor-Schein); Utopia.

\section{REFERÊNCIAS}

ADORNO, T.W. Teoria estética. Lisboa: Edições 70, 2008.

. Ästhetische Theorie, Gesammelte Schriften 7. Frankfurt a. M.: Suhrkamp Verlag, 1970. 
; HORKHEIMER, M. Dialética do esclarecimento: fragmentos filosóficos. 2ª ed. Rio de Janeiro: Zahar, 1986. BLOCH, Ernst. O Princípio Esperança. Tradução de Werner Fuchs. Rio de Janeiro: EDUERJ/Contraponto, 2005. V. 1 .

. O Princípio Esperança. Tradução de Werner Fuchs. Rio de Janeiro: EDUERJ/Contraponto, 2006. V. 2 .

- O Princípio Esperança. Tradução de Werner Fuchs. Rio de Janeiro: EDUERJ/Contraponto, 2006. V. 3 .

. Das Prinzip Hoffnung. Frankfurt: Suhrkamp Verlag, 1979, I, II e III.

. Geist der Utopie. Munich-Leipzig: Duncker \& Humblot, 1918.

. Héritage de ce temps. Paris: Payot, 1978.

. Discussões sobre o expressionismo. In: MACHADO, C. Um capítulo na história da modernidade estética: debate sobre o expressionismo. São Paulo: Unesp, 1998. P. 171-193.

. Something's Missing: a Discussion Between Ernst Bloch and Theodor W. Adorno on the Contradictions of Utopian Longing (1964). In BLOCH, Ernst. The Utopian Function of Art and Literature: Selected Essays. Translated by Jack Zipes and Frank Mecklenburg. Studies in contemporary German social thought. Cambridge, Mass.: MIT Press, 1988.

FURTER, Pierre. Dialética da esperança. Rio de Janeiro: Paz e Terra, 1974. 
LÖWY, Michel. Ernst Bloch e Theodor Adorno: luzes do Romantismo. In: Cadernos Cemarx, Campinas, n. 6, p. 1127 , 2009.

Disponível em: $<$ http://www.ifch.unicamp.br/ojs/index.php/cemarx/article /viewFile/1084/794 > . Acesso em: março de 2013.

- Adorno: um pessimista com a razão: $\mathrm{O}$ olhar de Arno Münster no seu Adorno. Une introduction. In: O Olho da História, Salvador (BA), n. 19, dezembro de 2012 .

- BLECHMAN, Max. Négativité et Utopie.In: Europe: revue littéraire mensuelle. T. W. A d o $\mathrm{r} n$ o/E r n s t Bloch. 86e année, n. 949, Mai de 2008, p. 03-05.

MACHADO, C. Um capítulo na história da modernidade estética. Debate sobre o expressionismo. São Paulo: Unesp, 1998.

MÜNSTER, Arno. Utopia, messianismo e apocalipse nas primeiras obras de Ernst Bloch. São Paulo: Unesp, 1997. 